\title{
Mixed problem with dynamical transmission condition for a one-dimensional hyperbolic equation with strong dissipation
}

\author{
Akbar Aliyev ${ }^{1}$ and Gulshan Shafieva ${ }^{2}$ \\ ${ }^{1}$ Institute of Mathematics and Mechanics of Azerbaijan National Academy of Sciences \\ ${ }^{2}$ Baku State University
}

September 11, 2020

\begin{abstract}
In this paper, we study a mixed problem for the nonlinear hyperbolic equation with a strong dissipation and a dynamical transmission condition. The existence and uniqueness theorems of local and global solutions are proved
\end{abstract}

\section{Hosted file}

AliyevShafiyeva_MMAS.pdf available at https://authorea.com/users/356799/articles/479601mixed-problem-with-dynamical-transmission-condition-for-a-one-dimensional-hyperbolicequation-with-strong-dissipation 